\title{
Aboriginal and non-aboriginal Australian former prisoners' patterns of morbidity and risk of hospitalisation
}

Jane E. Lloyd ${ }^{1 *}$, Elizabeth McEntyre ${ }^{2}$, Eileen Baldry², Julian Trofimovos ${ }^{2}$, Devon Indig ${ }^{3}$, Penelope Abbott ${ }^{4}$, Jennifer Reath" ${ }^{4}$ Kathy Malera-Bandjalan ${ }^{5}$ and Mark F. Harris ${ }^{1}$

\begin{abstract}
Background: People who have been in custody are more likely to experience multiple, long standing health issues. They are at high risk of illness and injury post release and experience poor access to health services both of which contribute to high rates of recidivism. The study was conducted to examine Aboriginal and non-Aboriginal former prisoners' risk of hospitalisation and rehospitalisation in the five years post release from custody and identified the common reasons for hospitalisations.

Methods: Common reasons for hospital admission were identified by conducting descriptive analysis of linked data, related to former prisoners, from NSW Ministry of Health and Corrective Services NSW. This relied upon admitted patient data for 1899 patients. Of this cohort, 1075 people had been admitted to hospital at least once and remained out of custody over a five year period. The independent variables we studied included age, sex, and whether or not the person was Aboriginal. We conducted univariate and multivariate analysis on the following dependent variables: number of admissions over five years after release; more than one admission; days between custody and first hospitalisation; and days between first and second hospitalisation.

Results: Mental and behavioural disorders, injuries and poisoning, and infectious or parasitic diseases were the three most common reasons for admission. Aboriginal and non-Aboriginal former prisoners had a broadly similar pattern of reasons for admission. Yet Aboriginal former prisoners were more likely than non-Aboriginal former prisoners to have a shorter mean interval between hospital admission and readmission (187 days compared to 259 days, $t=2.90, p-0.004$ ).

Conclusions: Despite poorer health among Aboriginal people, there were broadly similar patterns of reasons for admission to hospital among Aboriginal and non-Aboriginal former prisoners. There may be a number of explanations for this. The cohort was not a representative sample of the NSW prison population. There was an overrepresentation of individuals with cognitive disability (intellectual disability, acquired brain injury, dementia, fetal alcohol spectrum disorder) in the study population, which may have impacted on this group accessing hospital health care. Alternatively perhaps there were fewer presentations to hospital by Aboriginal former prisoners despite a greater need. The shorter interval between hospital admission and readmission for Aboriginal former prisoners may suggest the need for better follow up care in the community after discharge from hospital. This presents an opportunity for primary health care services to work more closely with hospitals to identify and manage Aboriginal former prisoners discharged from hospital so as to prevent readmission.
\end{abstract}

Keywords: Aboriginal Australians, Access to health care, Hospitalisation, Criminal justice

\footnotetext{
* Correspondence: j.lloyd@unsw.edu.au

${ }^{1}$ Centre for Primary Health Care and Equity, Faculty of Medicine, University of

New South Wales, Sydney, Australia

Full list of author information is available at the end of the article
} 


\section{Background}

Aboriginal people are over-represented in the Australian criminal justice system and their rate of incarceration is increasing. In the March quarter 2016, the proportion of Aboriginal prisoners represented $28 \%$ of the total fulltime prisoner population, whereas Aboriginal people comprise $2 \%$ of the general Australian population aged 18 years and over. The rate of Aboriginal incarceration is increasing. Between the March quarter 2015 and the March quarter 2016 the imprisonment rate for Aboriginal Australians increased by 7\% [1]. Aboriginal Australians are more likely to cycle in and out of prison on remand or by serving multiple short sentences $[2,3]$.

Aboriginal people who have been in custody are likely to experience multiple, long standing health issues [4], and to be at a high risk of illness and injury post release $[5,6]$. In particular many Aboriginal people who have been in custody have a mental illness and/or a cognitive disability [7], a substance abuse disorder and a chronic condition [8]. Aboriginal people in custody have higher rates of mental illness than other Aboriginal Australians [9]. Aboriginal Australians have been deeply negatively affected over generations by colonisation, dispossession, having children stolen, being discriminated against and being subjected to multiple forms of institutionalisation [10]. Aboriginal Australians' overrepresentation in the criminal justice system cannot be understood without this knowledge [11, 12].

\section{The impact of incarceration on health}

Health services in prisons are not fully equipped to manage mental illness and other disabilities [13]. Often mental illness and anxiety and some forms of physical illness such as diabetes are hidden problems that have gone undetected prior to imprisonment and therefore stay undetected by both the prisoner and the criminal justice system in the context of more immediate concerns. This is especially true during transition into and out of prison on remand or short sentence where it becomes difficult to prioritise health among more pressing demands.

In addition to pre-existing poorer health among Aboriginal Australians entering the criminal justice system, being imprisoned can also worsen ill health although for some it is an opportunity to receive health care. Being incarcerated is another form of trauma that is likely to negatively impact one's health and wellbeing [14]. In New South Wales (NSW), health services to prisoners are provided through the public health system, by the Justice Health and Forensic Mental Health Network. However the prison environment is not geared to deal with multi-morbidities; Corrective Services' concerns for security and accommodating prisoners can take precedence over the health and welfare of prisoners [14].
The impact of poor health and poor access to health care on recidivism

An important factor influencing recidivism is the level of services available for people on release from prison [15]. In Australia, a former prisoner's access to health care and social support services such as housing varies depending on their custody classification and place of residence. Sentenced prisoners have better access to post release programs than those on remand [5] and short sentence prisoners (under one year) have little access to services compared with those on longer sentences [12]. Aboriginal people are likely to have more short sentences and remand episodes than non-Aboriginal people [3] and so have poorer access to and use of in-prison services. Without access to comprehensive health care and social support services, Aboriginal people are more likely to return to the same environments that led to their incarceration in the first place, thus contributing to higher rates of recidivism and hospitalisation. Particular concerns include the poor ongoing management of mental illness and substance misuse, experiences of trauma and marginalisation and difficulty securing housing [16] and employment. Accessing culturally safe primary health care [17] that deals with trauma, drug and alcohol, family violence and breakdown [18] on release is necessary to support former Aboriginal prisoners to stay out of the criminal justice system.

To date research on the hospitalisation of former prisoners has tended to focus on the immediate period after release from custody and the need for immediate transition support $[6,19]$. Access to quality in-custody health care and to immediate post release care for Aboriginal Australians is important. So too is what happens in the five years post release particularly the extent to which institutions such as hospitals and primary health care services meet the needs specific of Aboriginal Australians. The aim of this study is to identify Aboriginal and nonAboriginal ex-prisoners' risk of hospitalisation and rehospitalisation in the five years post release from custody and to detect the common reasons for hospitalisations.

\section{Methods}

This primary health care and criminal justice project involved a partnership between the University of New South Wales, the Aboriginal Medical Service Western Sydney, Western Sydney University, the University of Technology Sydney and the Justice Health \& Forensic Mental Health Network. The project was designed with input from Aboriginal and non-Aboriginal chief investigators. The research team included academics, primary health care providers, policy officers, an Aboriginal mental health social worker and a criminologist. This mixed method study had three phases: a systematic review, indepth interviews and a linked data set analysis. This 
paper reports on the findings from the linked data set analysis.

One of the chief investigators (EB) had previously developed a Mental Health Disorders and Cognitive Disability (MHDCD) linked dataset. This includes a cohort of 2731 people (673 of whom are Aboriginal) drawn from the 2001 NSW Inmate Health Survey and from the NSW Department of Corrective Services Disability Service Database, and links all available de-identified administrative records from Criminal Justice and Human Service agencies in NSW. These agencies include Corrective Services NSW, Juvenile Justice NSW, the NSW Police Force, Justice Health \& Forensic Mental Health Network, the NSW Bureau of Crime Statistics and Research (BOCSAR), Legal Aid NSW, Family \& Community Services, Ageing Disability and Home Care, Housing NSW and NSW Ministry of Health. Analysing information from the linked data set received ethics approval in 2006 from the Aboriginal Health and Medical Research Council of NSW (People with Mental Health Disorders and Cognitive Disability in the Criminal Justice System 569/06).

Linked data from the Admitted Patient Data Collection from the NSW Ministry of Health and Corrective Services NSW were analysed to identify the major reasons for hospitalisation (according to all the ICD-10 diagnosis codes in the reason for admission) and to better understand Aboriginal and non-Aboriginal former prisoners' risk of hospitalisation and rehospitalisation.

We examined a five-year period post release from custody to increase understanding of the ongoing health of former prisoners and to identify whether the experiences of Aboriginal former prisoners were different to those of non-Aboriginal former prisoners over the same time period.

Of the 2731 people in the cohort, the dataset contained admitted patient data for 1899 patients. When examining the reasons for hospital admission we utilised data from the 1899 patients. However when examining the risk of hospitalisation only 1075 of the 1899 patients fitted our inclusion criteria of remaining out of custody and having at least one hospitalisation over a five-year period from the 3rd April 2003 to the 3rd April 2008. This time period represents five years prior to the date when data was extracted from the administrative data sources. Cohort members who were re-incarcerated were excluded from the analysis so that everyone had an equal chance of being hospitalised (Fig. 1).

Descriptive analysis was conducted on reasons for hospitalisation. This was presented in graphic form for the three most common classes of condition (according to ICD-10 categories) for hospital admission. We then analysed factors associated with hospital admission $(0=$ only one hospitalisation, 1 = more than one hospitalisation).

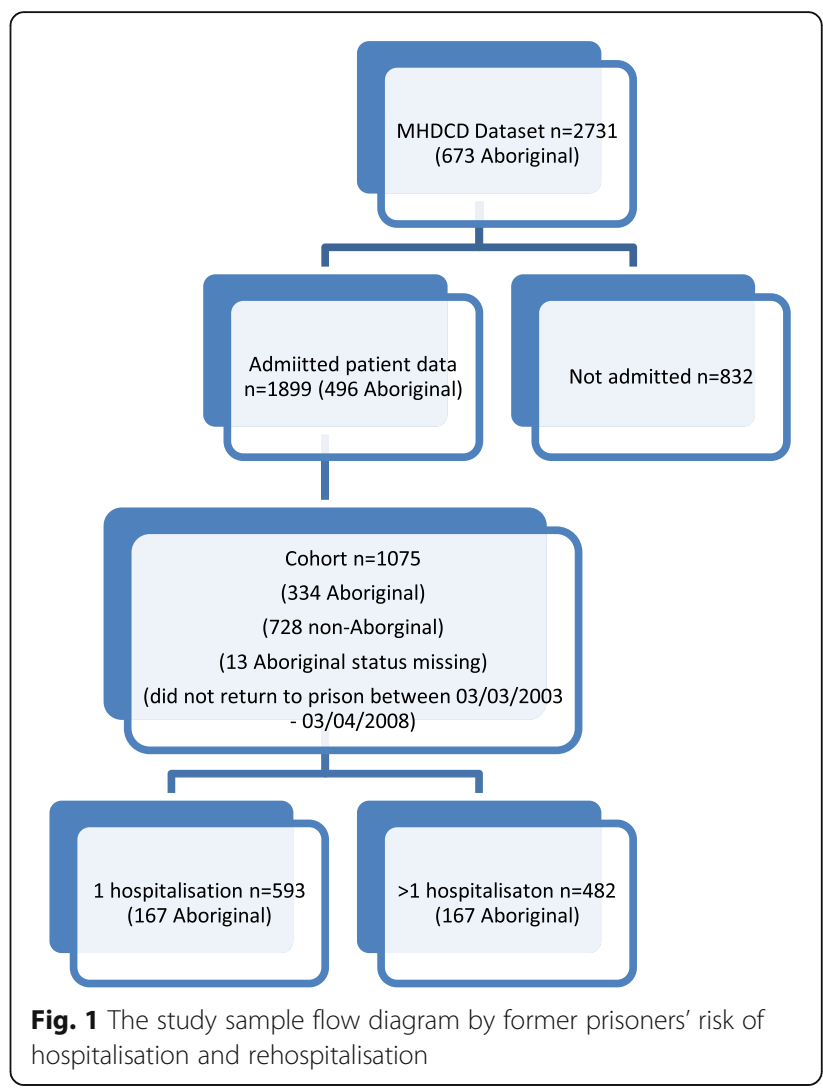

The independent variables were age $(1=35$ years and under, $2=36$ years and over), sex $(1=$ male, $2=$ female $)$, and whether or not the person was Aboriginal $(1=$ Aboriginal, $0=$ not Aboriginal). The age over 35 was chosen as the cut off for the categorisation because the incidence of premature cardiovascular disease increases from age 35 among Aboriginal people. We conducted univariate and multivariate analysis on the following dependent variables: number of admissions over 5 years after release (regression); more than one hospital admission (logistic regression); days between custody and first hospitalisation (poisson regression); and days between first and second hospitalisation (poisson regression). The analysis identified patterns of morbidity and ex-prisoners' risk of hospitalisation post release from custody, and in particular identified similarities and differences between Aboriginal and non-Aboriginal participants.

\section{Results}

The results are divided into two sections: Reasons for hospitalisations, and the Frequency of hospitalisation in the five years post release from custody. The first section includes all former prisoners with hospital admission data (whether they are re-incarcerated or not) and the second section is only for those who have not been reincarcerated over the five year period specified. 


\section{Reasons for hospitalisations}

The three most common ICD-10 categories of reasons for hospitalisation were mental and behavioural disorders, injuries and poisoning and certain other consequences of external causes, and infectious or parasitic diseases. The frequencies of the top four specific diagnoses in these categories are listed in Table 1.

The mean number of ICD-10 diagnosis codes per admission was 4.98. There were no significant differences in the number by Aboriginality. Instead Aboriginal and non-Aboriginal former prisoners had broadly similar reasons for admission to hospital. Females had more diagnosis codes than males (mean 5.62 compared to 4.87, $p<0.01)$ and those age more than 35 years had more morbidities than those 35 years or younger (mean 5.57 compared to $4.60, p<0.001)$. This was confirmed by multivariate linear regression modelling.

While there were similar reasons for admission to hospital among former prisoners, Aboriginal participants had higher rates of infectious diseases caused by bacteria, viruses and other infectious agents than nonAboriginal former prisoners (23\% versus 18\%).

\section{Multi-morbidity}

Figure 2 shows the proportion of admissions for Aboriginal people that related to one or more of the three categories of diagnosis. Figure 3 shows the proportion of admissions for non-Aboriginal people that related to one or more of the three categories of diagnosis. The pattern was similar for Aboriginal and non-Aboriginal former prisoners. However, more non-Aboriginal than Aboriginal admissions were for mental and behavioural disorders alone (22\% vs $17 \%)$. By contrast more Aboriginal (9\%) than non-Aboriginal admissions (2\%) were for both injury/poisoning and infectious disease.

\section{Frequency of hospitalisation}

There were 1075 people in the dataset with one or more hospitalisations who did not return to prison over the five year period (April 2003- April 2008). Of these 593 people $(55.2 \%)$ had only one hospitalisation and 482 (44.8\%) had more than one hospitalisation. The mean number of hospitalisations over the 5 year period was 1.98. The mean age of former prisoners with only one hospitalisation was 34.9 years (SD 9.6), and the mean age of former prisoners with more than one hospitalisation was 33.1 years (SD 7.2).

A cohort of 476 met the criteria of having more than one hospitalisation in the five year period after release from custody. Among those who had more than one hospitalisation, 394 were males (81.7\%) and 88 were females (18.3\%), and 167 identified as being Aboriginal Australians (35.1\%). For 13 cases in the cohort of 1075 information on Aboriginal status was missing. See Table 2 below:

There was a significant difference in the likelihood of hospitalisation on more than one occasion by gender

Table 1 Frequency distribution table that presents the most frequent reasons for hospitalisation in three main ICD-10 categories

\begin{tabular}{|c|c|c|c|c|}
\hline & \multicolumn{2}{|c|}{$\begin{array}{l}\text { Non Aboriginal } \\
(n=1403)\end{array}$} & \multicolumn{2}{|c|}{$\begin{array}{l}\text { Aboriginal } \\
(n=496)\end{array}$} \\
\hline & $\mathrm{N}$ & $\begin{array}{l}\text { Ratio of admission per } \\
\text { head of population }\end{array}$ & $\mathrm{N}$ & $\begin{array}{l}\text { Ratio of admission per } \\
\text { head of population }\end{array}$ \\
\hline \multicolumn{5}{|l|}{ Mental and Behavioural Disorders } \\
\hline Mental and behavioural disorders due to psychoactive substance use & 855 & 0.61 & 367 & 0.74 \\
\hline Schizophrenia, schizotypal and delusional disorders & 285 & 0.20 & 123 & 0.25 \\
\hline Disorders of adult personality and behaviour & 268 & 0.19 & 107 & 0.22 \\
\hline Neurotic, stress-related and somatoform disorders & 259 & 0.18 & 96 & 0.19 \\
\hline \multicolumn{5}{|l|}{ Injury, poisoning and certain other consequences of external causes } \\
\hline Injuries to the head & 367 & 0.27 & 152 & 0.31 \\
\hline Poisoning by drugs, medicaments and biological substances & 256 & 0.18 & 121 & 0.24 \\
\hline Injuries to the wrist and hand & 241 & 0.17 & 97 & 0.20 \\
\hline Injuries to the elbow and forearm & 152 & 0.11 & 65 & 0.13 \\
\hline \multicolumn{5}{|l|}{ Infectious and Parasitic diseases } \\
\hline Bacterial, viral and other infectious agents & 188 & 0.18 & 113 & 0.23 \\
\hline Viral hepatitis & 181 & 0.17 & 66 & 0.13 \\
\hline Other bacterial diseases & 36 & 0.03 & 26 & 0.05 \\
\hline Intestinal infectious diseases & 27 & 0.03 & 10 & 0.02 \\
\hline
\end{tabular}

a (frequency of the different ICD-10 diagnoses)/number of individuals in database for whom we had admitted patient data (1403 non-Aboriginal and 496 Aboriginal $=1899$ ) 


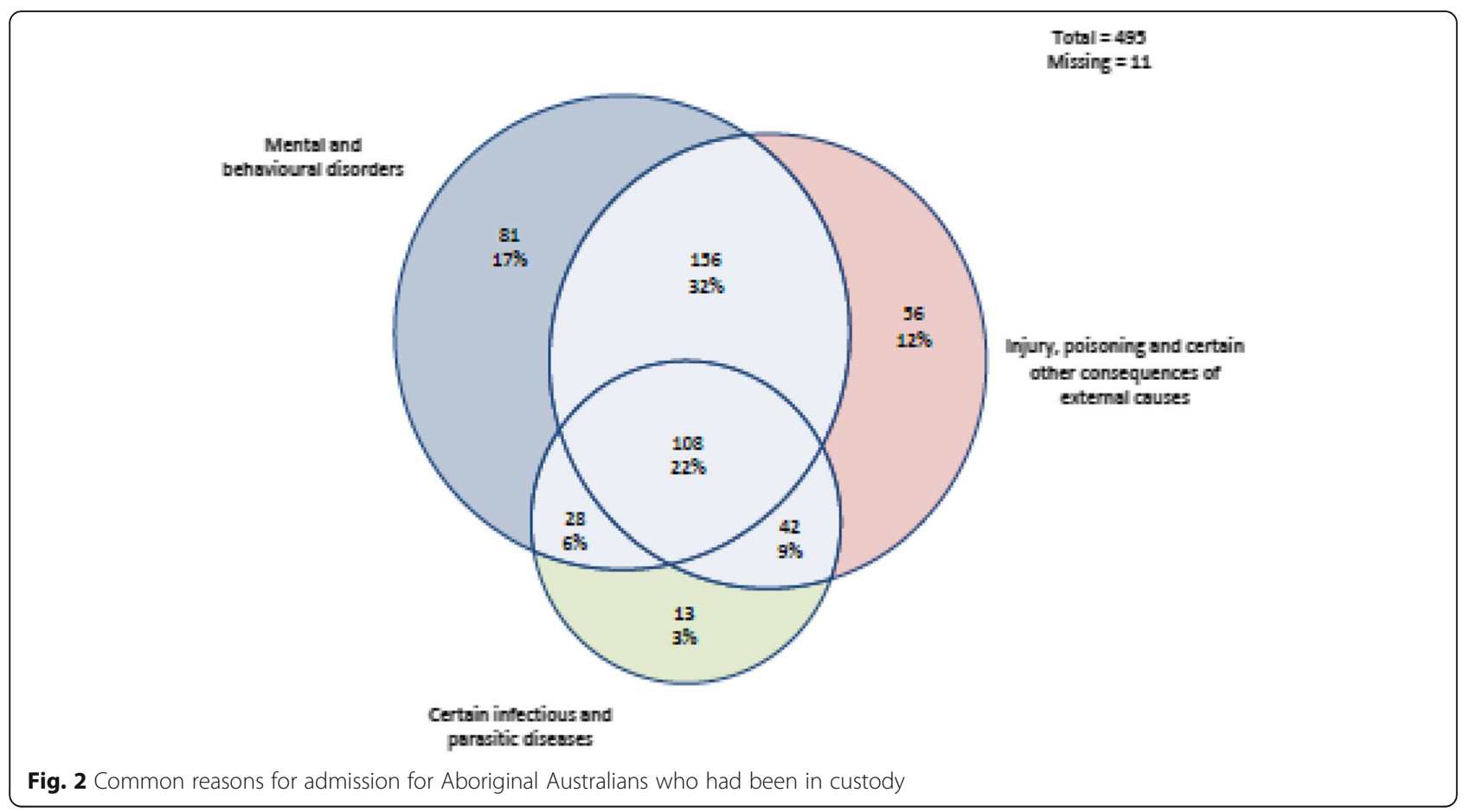

(females $56 \%$ versus males $43 \% p=0.03$ ). Aboriginal former prisoners were slightly more likely to be in hospital more than once compared to non-Aboriginal former prisoners $(50 \%$ versus $42 \% p=0.03)$. Females, younger individuals and Aboriginal Australians were more likely to be admitted to hospital more than once compared to males, older individuals and nonAboriginal former prisoners.

In multivariate logistic regression analysis the likelihood of admission more than once was not influenced

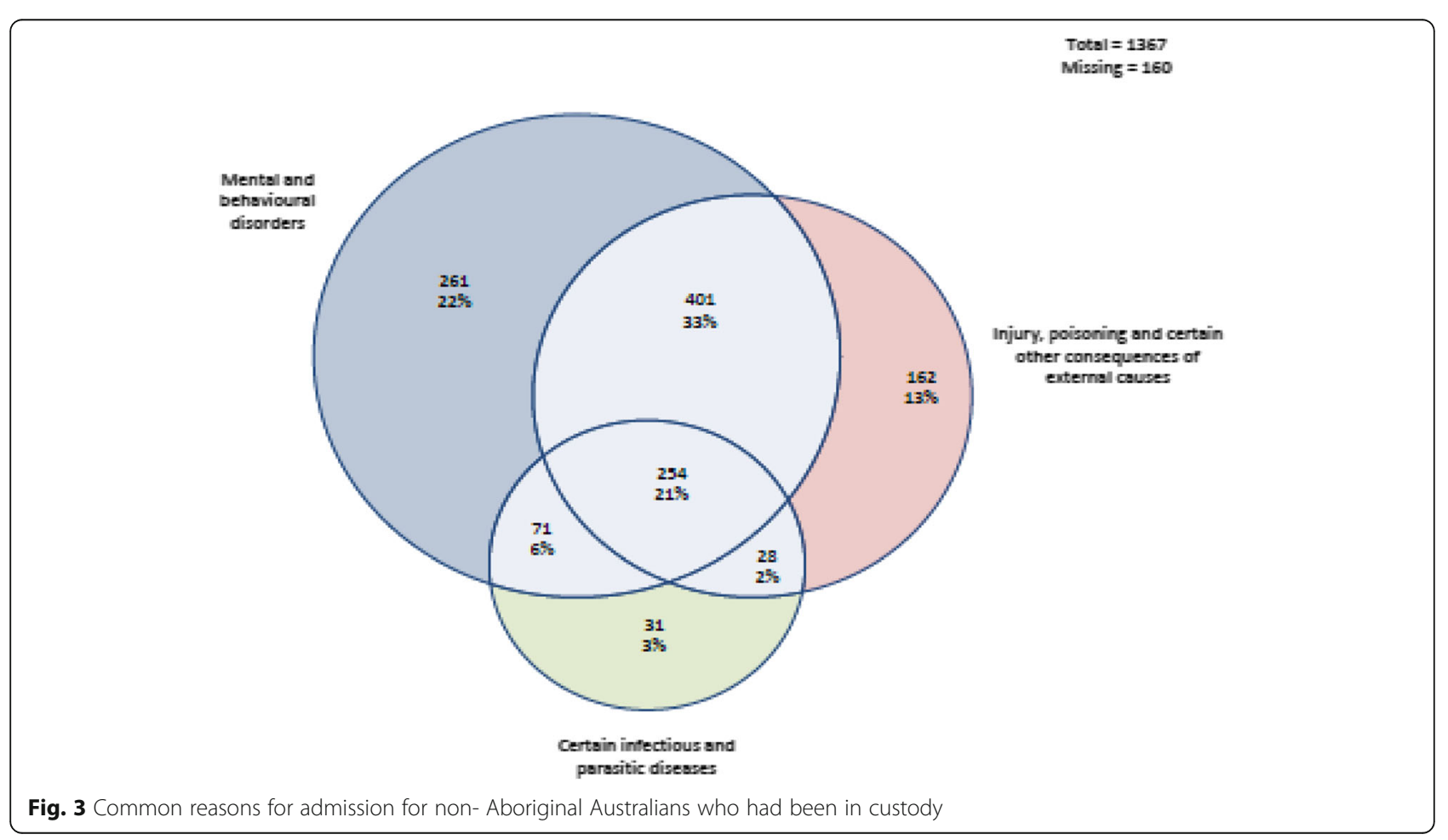


Table 2 Frequency distribution table that presents the differences between Aboriginal and non-Aboriginal former prisoners admitted to hospital more than once

\begin{tabular}{lll}
\hline $\begin{array}{l}\text { Hospitalisations in } \\
\text { the five-year period }\end{array}$ & $\begin{array}{l}\text { Aboriginal Australians } \\
(N=334)\end{array}$ & $\begin{array}{l}\text { Non-Aboriginal Australians } \\
(N=728)\end{array}$ \\
\hline Once & $167(50 \%)$ & $419(58 \%)$ \\
More than once & $167(50 \%)$ & $309(42 \%)$ \\
\hline
\end{tabular}

by Aboriginality after adjusting for gender and age group (Table 3). However the association for gender and age remained significant.

\section{Interval between release from custody and first hospitalisation}

The mean interval between release from custody and first hospitalisation was 353 days. This was significantly longer for those over 35 years of age (382 days) compared with those 35 and under (334 days; $p=0.02$ ). There were no significant differences between Aboriginal and non-Aboriginal former prisoners or between male and female former prisoners for time to first hospitalisation. This was confirmed in generalised linear modelling adjusted for age group, sex and Aboriginality.

\section{Interval between hospitalisation and rehospitalisation}

The mean interval between first and second hospitalisation was 239 days. The median was 71 days. For Aboriginal former prisoners the mean was 187 days compared to 259 days for non-Aboriginal former prisoners $(t=2.90, p-0.004)$. There was no significant difference for males and females, however older prisoners aged 35 years or more had a longer interval $(t=3.5$, $p<0.001)$ than younger former prisoners. Aboriginality remained significant after adjustment for age and sex in regression analysis (Table 4).

\section{Discussion}

\section{Reasons for hospitalisation}

While the reasons for hospitalisation among former prisoners were broadly similar, there were some notable differences between Aboriginal and non-Aboriginal former prisoners. More Aboriginal than non-Aboriginal former prisoners' admissions to hospital were for both injury/ poisoning and infectious disease than non-Aboriginal

Table 3 Multivariate logistic regression analysis: Factors associated with more than one hospitalisation

\begin{tabular}{llcll}
\hline Variable & Odds Ratio $(95 \% \mathrm{Cl})$ & Significance $^{*}$ & $\mathrm{~B}$ & S.E \\
\hline Aboriginal Australians & $0.79(0.53-1.06)$ & 0.09 & -.230 & .135 \\
Female gender & $1.59(1.25-1.94)$ & $0.009^{*}$ & .465 & .177 \\
Age group $>35$ & $0.98(0.96-0.99)$ & $0.001^{*}$ & -.025 & .007 \\
\hline
\end{tabular}

*means that the $p$ value is less than or equal to 0.05
Table 4 Poisson regression to identify factors associated with the number of days between first and second hospitalisation

\begin{tabular}{lll}
\hline Variable & Beta coefficient (St Error) & Significance * \\
\hline Aboriginal Australians & $-0.30(0.13)$ & $0.03 *$ \\
Male gender & $-0.18(0.13)$ & .17 \\
Age group $>35$ & $0.40(0.11)$ & $0.001^{*}$ \\
\hline
\end{tabular}

*means that the $p$ value is less than or equal to 0.05

admissions (9\% versus 2\%). This suggests that Aboriginal former prisoners are more likely to have multiple conditions, thus making their health care more complex to manage. Aboriginal former prisoners had higher rates of hospitalisation for bacterial, viral and other infections than non-Aboriginal former prisoners (23\% versus $18 \%$ ). With early and effective management these disease hospitalisations can often be prevented. This finding suggests that Aboriginal former prisoners may delay seeking health care until it becomes absolutely necessary or are unable to access health care.

Inequitable access to health services for Aboriginal Australians [20, 21] may also explain the finding of broadly similar reasons for admissions to hospital among Aboriginal and non-Aboriginal former prisoners despite the poorer health of Aboriginal people. Not presenting to hospitals does not necessarily mean populations are well. It is possible that Aboriginal former prisoners may be less likely to present to hospital despite a greater need.

Poor access to health care and cycling in and out of prison may be part of a lifetime of institutional recycling fuelled by exclusion from continuity of appropriate support and care in schools, prisons, hospitals or other mainstream institutions [16, 22]. Whilst this exclusion may not be intentional, it is a consequence of failing to understand and address the particular circumstances and needs of Aboriginal Australians [23].

\section{The interval between the first and second admission to hospital}

We found that Aboriginal former prisoners with a hospital admission over a five year period are more likely to have a shorter interval between the first and second admission to hospital. For Aboriginal former prisoners the mean was 187 days compared to 259 days for nonAboriginal former prisoners $(\mathrm{t}=2.90, p-0.004)$. This may be because Aboriginal former prisoners' initial problems were not dealt with effectively either in hospital or after hospital discharge in the community and that Aboriginal former prisoners had poorer access to health care due to geographical and socio-economic reasons [7]. This suggests a need to ensure access to effective care by facilitating connections with primary care providers who would help the person manage their health, in order to 
prevent rehospitalisation and that this should be actively considered and facilitated at times of leaving prison and hospital.

\section{Linkage and coordination between services}

The shorter interval between hospital admission and readmission for Aboriginal former prisoners may indicate a failure of hospital follow-up care and also presents an opportunity for primary health care to do more to actively support Aboriginal former prisoners discharged from hospital who may be vulnerable to discontinuity of care [24].

For Aboriginal Australians primary health care includes medical and health services provided in the community either through Aboriginal Community Controlled Health Services or through private general practice [25]. The role of primary health care providers extends beyond medical care to include recognition of the social determinants of health such as housing and employment and the need to work with other professionals and organisations to address these needs [26].

If patients are not adequately followed up and managed by primary health care providers then their conditions are unlikely to be adequately controlled, resulting in readmission to hospital. More vigorous support and referral on release from prison might assist to link Aboriginal exprisoners better to primary health care systems and reduce hospitalisations in the first place. Active follow-up and communication post discharge from hospital is required both with patients and their primary care provider to ensure that the provider is aware of the patient's health status and is able to make a plan for the patient's follow-up and ongoing care. A study of presentations to Emergency Departments in Victoria found that Aboriginal Australians were less likely to nominate a general practitioner [21], therefore if patients do not regularly see a provider, this needs to be suggested and arranged if the person so wishes.

\section{Complex health issues}

Aboriginal former prisoners are likely to suffer complex health issues [23] and face numerous barriers to accessing culturally appropriate primary health care. Adequate long term support for Aboriginal former prisoners is likely to help prevent hospital admissions and re-incarceration. Access to good case management, culturally appropriate and continuous health care and family support are likely to reduce incarceration rates and to improve health $[8,22,27,28]$. However there is a difference between knowing what is required in order to support Aboriginal former prisoners, and the reality of delivering such intensive and long term services. Health and social support services need to be person focused rather than disease or condition focused and are likely to require a 'wrap around' approach that includes services such as housing, life skills, parenting skills, mental health services, drug and alcohol and disability support $[15,29]$. Primary health care is well placed to coordinate access to such services, but needs adequate infrastructure and funding in order to do so [14]. Place is another vital factor in Aboriginal former prisoners being able to access and receive appropriate health care as Aboriginal people are more highly concentrated in disadvantaged suburbs and rural areas.

The cohort used in this research was not a representative sample of the NSW prisoner population. Instead the cohort included an overrepresentation of individuals with cognitive disability. Therefore a limitation of this study is that the rates of cognitive disability are likely to be higher in this cohort than the general former prisoner population. This may have influenced the rate of admission for mental and behavioural disorders. Significance testing was not done on the reasons for hospitalisation as depicted in the Venn diagrams and therefore these findings should be treated with caution. A major limitation is also that the study was limited to people who remained out of custody over a five year period. The health issues of people who cycle in and out of prison (of which Aboriginal people are significantly overrepresented) would be worse, including potentially more hospital admissions when they are in custody. This suggests these findings are an underestimate of the morbidity and complexity of the prisoner population as a whole.

\section{Conclusions}

Despite poorer health among Aboriginal people there were broadly similar patterns of reasons for admission to hospital among Aboriginal and non-Aboriginal former prisoners.

Aboriginal Australians released from custody and who were not re-incarcerated over a five year period after release, were more likely to be readmitted to hospital in a shorter interval in the five years post release compared to their nonAboriginal peers. The cycle of rehospitalisation may be remediated through active follow up in the community both during transition from prison as well as on release from hospital. A more proactive approach to improving access to comprehensive, appropriate and quality primary health care in the community for Aboriginal former prisoners provides the foundation for ongoing management and prevention of chronic conditions amongst this at risk group.

Adopting a longer term view of access to health care for Aboriginal former prisoners - rather than just focussing on the immediate period after release from custody - may be important in preventing a revolving door of hospitalisation.

\section{Abbreviations}

BOCSAR: NSW bureau of crime statistics and research; ICD-10: International classification of diseases - tenth edition; MHDCD: Mental health disorders and cognitive disability; NSW: New South Wales 


\section{Acknowledgements}

The linked data set analysis was one arm of a larger research project that was funded by the Australian Primary Health Care Research Institute. The research project involved a partnership between the University of New South Wales, the Aboriginal Medical Service Western Sydney, the Western Sydney University and the University of Technology Sydney.

\section{Funding}

The research project was funded by the Australian Primary Health Care Research Institute. This paper used the MHDCD linked dataset created from the data gathered during the two Australian Research Council Linkage projects LP0669246 and LP100200096.

\section{Availability of data and materials}

The dataset analysed during the study is not publicly available due to ethics requirements.

\section{Authors' contributions}

$J L$ participated in the design of the study, the interpretation of the results and prepared the initial draft of the manuscript. EM participated in the design of the study, the interpretation of the results and contributed to drafting the manuscript. EB acquired the data, contributed to the design of the study, and critically revised the manuscript for important intellectual content. JT performed the statistical analysis and contributed to the interpretation of the results. DI, PA, JR and KMB contributed to the design of the study and critically revised the manuscript for important intellectual content. MFH contributed to the design of the study, the interpretation of the results and to drafting the manuscript. All authors read and approved the final manuscript.

\section{Competing interests}

The authors declare that they have no competing interests.

\section{Consent for publication}

Not applicable.

\section{Ethics approval and consent to participate}

Ethics approval was granted from the Aboriginal Health and Medical Research Council. Reference number: 569/06.

\section{Author details}

'Centre for Primary Health Care and Equity, Faculty of Medicine, University of New South Wales, Sydney, Australia. ${ }^{2}$ School of Social Sciences, Faculty of Arts and Social Sciences, University of New South Wales, Sydney, Australia. ${ }^{3}$ School of Public Health and Community Medicine, Faculty of Medicine, University of New South Wales, Sydney, Australia. ${ }^{4}$ Department of General Practice, Faculty of Medicine, Western Sydney University, Sydney, Australia. ${ }^{5}$ Aboriginal and Islander Health Worker Journal, Sydney, Australia.

Received: 18 August 2016 Accepted: 12 December 2016 Published online: 05 January 2017

\section{References}

1. Australian Bureau of Statistics. Corrective services march quarter 2016 Canberra: Australian Bureau of Statistics; 2016. Contract No.: 4512.0.

2. Australian Bureau of Statistics. Prisoners in Australia. Canberra: Australian Bureau of Statistics and Australian Government Publishing Service; 2014.

3. Baldry E, Cunneen C. Imprisoned Indigenous women and the shadow of colonial patriarchy. Aust N Z J Criminol. 2014;47:276-98.

4. Indig D, McEntyre E, Page J, Ross B. 2009 inmate health survey: aboriginal health report. Sydney: Justice Health; 2011.

5. Stewart LM, Henderson CJ, Hobbs MST, Ridout SC, Knuiman MW. Risk of death in prisoners after release from jail. Australian and New Zealand Journal of Public Health. 2004;28(1):32-6.

6. Alan J, Burmas M, Preen D, Pfaff J. Inpatient hospital use in the first year after release from prison: a Western Australian population-based record linkage study. Aust N Z J Public Health. 2011;35(3):264-9.

7. Baldry E, Dowse L, Clarence M. People with intellectual and other cognitive disability in the criminal justice system. In: Report for NSW family and community services ageing, disability and home care. 2012
8. The SPRINT Project Team. How might the primary health care system better support aboriginal people released from the criminal justice sysstem: a systematic literature review. Sydney: University of New South Wales; 2013.

9. Heffernan EB, Andersen KC, Dev A, Kinner S. Prevalence of mental illness among aboriginal and Torres strait islander people in Queensland prisons. Med J Aust. 2012;197(1):37-41.

10. Dudgeon P, Wright M, Paradies Y, Garvey D, Walter I. The social, cultural and historical context of aboriginal and Torres strait islander Australians. In: Purdue N, Dudgeon P, Walker R, editors. Working together: aboriginal and Torres strait islander mental health and wellbeing: principles and practice. Canberra: Commonwealth of Australia; 2010.

11. Blagg H. Crime, aboriginality and the decolonisation of justice. Leichhardt: Hawkins Press; 2008

12. Cunneen C, Baldry E, Brown D, Brown M, Schwartz M, Steel A. Penal culture and hyperincarceration: the revival of the prison. Nelken D, editor. Penal Culture: Transmission, Normalisaton and Reproduction. Surrey, England: Ashgate Publishing Limited; 2013.

13. Baldry E, Clarence M, Dowse L, Trollor J. Reducing vulnerability to harm in adults with cognitive disabilities in the Australian criminal justice system. Journal of Policy and Practice in Intellectual Disabilities. 2013;10(3):222-9.

14. The SPRINT Project Team. Primary health care services better meeting the needs of aboriginal Australians transitioning from prison to the community: SPRINT final report. Sydney: University of New South Wales; 2013.

15. Borzycki M. Interventions for prisoners returning to the community. Canberra: Attorney-General's Department; 2005.

16. Baldry E, McDonnell D, Maplestone P, Peeters M. Ex-prisoners, homelessness and the state in Australia. Aust N Z J Criminol. 2006;39(1):20-33.

17. Kinner S, Williams M, editors. Post-release experiences of prisoners in Queensland: implications for community and policy. Proceedings Social Change in the 21st Century Conference 2006; 2006; Queensland University of Technology: University of Queensland.

18. Willis M. Reintegration of Indigenous prisoners: key findings. Trends ssues Crime Crim Just. 2008:364:1-6.

19. Kinner SA, Lennox N, GM W, Carroll M, Quinn B, Boyle FM, et al. Randomised controlled trial of a service brokerage intervention for ex-prisoners in Australia. Contemp Clin Trials. 2013;36(1):198-206.

20. Anderson K, Devitt J, Cunningham J, Preece C, Jardine M, Cass A. If you can't comply with dialysis, how do you expect me to trust you with transplantation? Australian Nephrologists' Views on Indigenous Australians 'non compliance' and their suitability for kidney transplantation. International Journal for Equity in Health. 2012;11:21. doi:10.1186/1475-9276-11-21.

21. Martin C, Smith T, Graudins A, Braitberg G, Chapman R. Characteristics of aboriginal and Torres strait islander presentations to thre Victorian emergency departments. Emerg Med Australas. 2013;25:573-9.

22. Baldry E. Women in transition: from prison to. Cur Issues in Crim Just. 2010;22(2):253-67.

23. Grace J, Krom I, Maling C, Butler T, Midford R. Review of Indigenous offender health. Australian Indigenous Health Reviews. 2011;8.

24. Kinner S. Passports to advantage: Health and capacity building as a basis for social integration. Flinders Journal of Law Reform. 2007/8:10:581-9.

25. Couzos S, Murray R. Aboriginal primary health care: an evidence-based approach. Melbourne: Oxford University Press; 2008.

26. Starfield B, Shi L, Macinko J. Contributions of primary care to health systems and health. Millbank Q. 2005;83(3):457-502.

27. Trotter C, Sheehan R, Naylor B. Monash university evaluation of programs for support of prisoners and Ex-prisoners. Melbourne: Monash University, Whitelion, Melbourne Citymission, Prison Network Ministries, Prison Fellowship Australia, Victoria; 2006.

28. Walsh T. Is corrections correcting? an examination of prisoner rehabilitation policy and practice in Queensland. Aust N Z J Criminol. 2006;39(1):109-33.

29. Calma T. Walking with the women - addressing the needs of indigenous women exiting prison. In: Social justice report 2004. Sydney: Human Rights and Equal Opportunity Commission; 2004. p. 11-66. 